IZA DP No. 7288

Estimating Obesity Rates in the Presence of Measurement Error

Donal O'Neill

Olive Sweetman

March 2013 


\title{
Estimating Obesity Rates in the Presence of Measurement Error
}

\author{
Donal O'Neill \\ National University of Ireland Maynooth \\ and IZA \\ Olive Sweetman \\ National University of Ireland Maynooth
}

Discussion Paper No. 7288

March 2013

IZA
P.O. Box 7240
53072 Bonn
Germany

Phone: +49-228-3894-0

Fax: +49-228-3894-180

E-mail: iza@iza.org

Any opinions expressed here are those of the author(s) and not those of IZA. Research published in this series may include views on policy, but the institute itself takes no institutional policy positions. The IZA research network is committed to the IZA Guiding Principles of Research Integrity.

The Institute for the Study of Labor (IZA) in Bonn is a local and virtual international research center and a place of communication between science, politics and business. IZA is an independent nonprofit organization supported by Deutsche Post Foundation. The center is associated with the University of Bonn and offers a stimulating research environment through its international network, workshops and conferences, data service, project support, research visits and doctoral program. IZA engages in (i) original and internationally competitive research in all fields of labor economics, (ii) development of policy concepts, and (iii) dissemination of research results and concepts to the interested public.

IZA Discussion Papers often represent preliminary work and are circulated to encourage discussion. Citation of such a paper should account for its provisional character. A revised version may be available directly from the author. 


\section{ABSTRACT}

\section{Estimating Obesity Rates in the Presence of Measurement Error}

Reliable measures of obesity are essential in order to develop effective policies to tackle the costs of obesity. In this paper we examine what, if anything, we can learn about obesity rates using self-reported BMI once we allow for possible measurement error. We combine selfreported data on BMI with estimated misclassification rates obtained from auxiliary data to derive upper and lower bounds for the population obesity rate for ten European countries. For men it is possible to obtain meaningful comparisons across countries even after accounting for measurement error. In particular the self-reported data identifies a set of low obesity countries consisting of Denmark, Ireland, Italy, Greece and Portugal and a set of high obesity countries consisting of Spain and Finland. However, it is more difficult to rank countries by female obesity rates. Meaningful rankings only emerge when the misclassification rate is bounded at a level that is much lower than that observed in auxiliary data. A similar limit on misclassification rates is also needed before we can begin to observe meaningful gender differences in obesity rates within countries.

JEL Classification: $\quad$ C13, C26, I14

Keywords: obesity, measurement error, bounds

Corresponding author:

Donal O'Neill

Department of Economics

NUI Maynooth

Maynooth, Co. Kildare

Ireland

E-mail: donal.oneill@nuim.ie 


\section{Introduction}

Obesity is an important cause of morbidity, disability and premature death and increases the risk for a wide range of chronic diseases (WHO, 2009). Reliable measures of obesity are essential in order to develop effective policies aimed at reducing the substantial costs associated with obesity. Using self-reported data from the European Community Household Panel (ECHP) Brunello et D’Hombres (2007) find substantial differences in the estimated obesity rates across nine European countries. For men during the period 1998-2001 the obesity rate ranges from a low of $5 \%$ in Ireland to a high of $10 \%$ in Finland. Denmark has the highest percentage of obese females (9\%), while Italy has the lowest (3\%). However, there is a large body of evidence that suggests that individuals underreport their weight and overstate their height when surveyed. Reporting error in height and weight can lead to estimates of obesity which are biased downwards (Conor Gorber et. al 2007). In addition there is some evidence that misclassification errors are increasing over time (Shiely et. al (2010). Errors in self-reported BMI may have serious consequences for policy making since these data are often used to generate national estimates of obesity and are in turn used by policy makers when setting priorities in health policy. Because of the limitations associated with self-reported measures, objective or direct measures of obesity have been recommended. However, the costs of obtaining these direct measures can sometimes be prohibitively high, and their intrusive nature may also impact on response rates. As a result reliance on self-reported BMI remains high. The WHO global infobase ${ }^{1}$, for example, is a data warehouse that collects, stores and displays information on chronic diseases and their risk factors for all WHO member states. This is a key source for international comparable statistics on a range of health indicators, including obesity rates. However, an examination of the underlying data sources reveals that for many countries in the database the information on obesity is based on self-reported measures of weight and height.

A number of correction strategies have been proposed to deal with the problem of measurement error in self-reported BMI. These include adjusting the self-reported threshold for obesity (Dauphinot et. al 2008, Madden 2012) and adjusting selfreported height and weight using prediction equations derived from auxiliary data (Nyholm et. al 2007). However, concerns have been raised as to the usefulness of

\footnotetext{
${ }^{1}$ For a detailed description see https://apps.who.int/infobase/.
} 
such corrections (e.g. Plankey et. al 997, Faeh et. al 2009). In this paper we adopt a different strategy. Rather than trying to correct self-reported BMI we examine, what, if anything one can learn about obesity rates based on self-reported BMI using only a minimal set of assumptions on the likely rates of misclassification. In particular we use self-reported data on height and weight, along with estimates of the misclassification rates obtained from auxiliary data, to derive upper and lower bounds for the population obesity rate in ten European countries. These bounds are sharp under the maintained assumptions, in that they exhaust all the information available in the self-reported data. We show that although the presence of measurement error reduces the information in the self-reported data, these data are still capable of producing meaningful comparisons across countries for men. When comparing male obesity rates we can still identify a set of low obesity countries consisting of Denmark, Ireland, Italy, Greece and Portugal and a set of high obesity countries consisting of Spain and Finland. It is more difficult however to rank countries by female obesity rates. For women meaningful rankings only emerge when the misclassification rate is bounded at a level that is substantially lower than the rate observed in practice.

2. Partial Identification of Obesity Rates in the presence of Measurement Error.

Obesity is typically measured using an individual's Body Mass Index (BMI), where $\mathrm{BMI}=$ weight in $\mathrm{kg} /$ height in $\mathrm{m}^{2}$. Individuals are classified as overweight if their BMI is between 25 and 30 and are classified as obese if their BMI exceeds 30. However, a number of studies have shown that self-reported height and weight suffer from serious measurement error problems. ${ }^{2}$ For example O’Neill and Sweetman (2012) report that while 14\% of a sample of Irish mothers were obese on the basis of self-reported data, the true obesity rate based on recorded data was $17.55 \%$. Likewise in a U.S. sample of women they found that the obesity rate was $17.47 \%$ when based on self-reported data compared to $22.70 \%$ using recorded data. The obesity rate based on self-reported data tends to be too low both because respondents over estimate their height and underestimate their weight.

\footnotetext{
${ }^{2}$ For a systematic review of the literature on measurement error in self-reported BMI see Connor Gorber et al (2007).
} 
Clearly measurement error in self-reported BMI can have a significant effect on measured obesity rates. In this paper we examine the informational content of selfreported BMI using bounds developed by Molinari (2007) and Nicoletti et. al (2011). These bounds are sharp in the sense that they exhaust all the available information given the sampling process and the maintained assumptions. In this paper we apply these techniques to estimate bounds for obesity rates across ten European countries. To understand the bounds let $X^{*}$, denote the true measure of BMI. Let $D_{X}{ }^{*}$ be a true obesity indicator equal to one if $X^{*}>30$ and zero otherwise. The true obesity rate is given by $\operatorname{Pr}\left(D_{X}{ }^{*}=1\right)=\operatorname{Pr}\left(X^{*}>30\right)$. However, in survey data we typically do not have access to $X^{*}$ but instead must rely on a self-reported (possibly mismeasured) measure $X_{i}$. The observed obesity indicator $D_{X}$ is equal to one if $X_{i}>30$ and is equal to zero otherwise and the observed obesity rate is $\operatorname{Pr}\left(D_{X}=1\right)=\operatorname{Pr}\left(X_{i}>30\right)$. When $X^{*} \neq X$ the observed BMI level is measured with error and ignoring this problem may lead to biased estimates of the population obesity rate. Molinari (2007) provides direct bounds for the true obesity rate by exploiting the following identity:

$$
\begin{aligned}
\operatorname{Pr}\left(D_{X}=1\right)= & \operatorname{Pr}\left(D_{X}=1 \mid D_{X^{*}}=1\right) \operatorname{Pr}\left(D_{X^{*}}=1\right) \\
& +\operatorname{Pr}\left(D_{X}=1 \mid D_{X^{*}}=0\right) \operatorname{Pr}\left(D_{X^{*}}=0\right)
\end{aligned}
$$

This is simply a statement of the law of total probability and places no restriction on the relationship between the true recorded measure of BMI and the self-reported measure. By imposing restrictions on the misclassification rates one can determine upper and lower bounds for the true obesity rate. The simplest bounds are obtained under the assumption that

Assumption 1: $\operatorname{Pr}\left(D_{X^{*}} \neq D_{X}\right) \leq \lambda_{1}<1$.

Under this assumption Molinari (2007) shows that tight bounds on $\operatorname{Pr}\left(D_{X^{*}}=1\right)$ are given by

$$
\begin{aligned}
& U B_{1}=\min \left\{\operatorname{Pr}\left(D_{X}=1\right)+\lambda_{1}, 1\right\} \\
& L B_{1}=\max \left\{\operatorname{Pr}\left(D_{X}=1\right)-\lambda_{1}, 0\right\}
\end{aligned}
$$

Alternative bounds follow from the imposition of alternative restrictions on the misclassification probabilities. In particular if we assume 
Assumption 2: $\operatorname{Pr}\left(D_{X}=1 \mid D_{X^{*}}=0\right) \leq \operatorname{Pr}\left(D_{X}=0 \mid D_{X^{*}}=1\right) \leq \lambda_{2}<1$.

then following Proposition 8 of Molinari (2007) we can establish the following set of bounds on the population obesity rate ${ }^{3}$

$$
\begin{array}{r}
\mathrm{UB}_{2}=\min \left\{\frac{\operatorname{Pr}\left(D_{X}=1\right)}{1-\lambda_{2}}, 1\right\} \\
L B_{2}=\max \left\{\frac{\operatorname{Pr}\left(D_{X}=1\right)-\lambda_{2}}{1-2 \lambda_{2}}, 0\right\}
\end{array}
$$

Assumption 2 states that it is more likely for obese people to report a BMI below the obesity threshold than it is for non-obese people to report a BMI above the threshold. This condition seems plausible though we will check its validity in the next section.

In addition, Nicoletti et. al (2011) derive alternative bounds by considering restrictions on the indirect misclassification probabilities, $\operatorname{Pr}\left(D_{X^{*}}=x^{*} \mid D_{X}=x\right)$. They consider the following monotonicity assumption:

Assumption 3: $\operatorname{Pr}\left(D_{X^{*}}=0 \mid D_{X}=1\right) \leq \operatorname{Pr}\left(D_{X^{*}}=1 \mid D_{X}=0\right) \leq \lambda_{3}<1$.

Under this assumption they derive the following bounds: ${ }^{4}$

$$
\begin{gathered}
\mathrm{UB}_{3}=\operatorname{Pr}\left(D_{X}=1\right)\left(1-\lambda_{3}\right)+\lambda_{3} \\
L B_{3}=\operatorname{Pr}\left(D_{X}=1\right)
\end{gathered}
$$

If we assume that Assumptions 1-3 hold at the same time then we can obtain narrower bounds by combing the information from the three individual bounds. The resulting identification interval is given by $\left\{\mathrm{LB}^{*}, \mathrm{UB}^{*}\right\}$ where $\mathrm{LB}^{*}$ is the maximum between $\left\{\mathrm{LB}_{1}, \mathrm{LB}_{2}, \mathrm{LB}_{3}\right\}$ and $\mathrm{UB}^{*}$ is the minimum between $\left\{\mathrm{UB}_{1}, \mathrm{UB}_{2}, \mathrm{UB}_{3}\right\}$. In the remainder of the paper we combine auxiliary data, which provides estimates of the $\lambda \mathrm{s}$, with the self-reported data on BMI from the ECHP in order to estimate these obesity bounds for ten European countries.

\footnotetext{
${ }^{3}$ These bounds hold provided $\operatorname{Pr}\left(D_{X}=1\right)<.5$ and $\lambda<.5$. The summary statistics show that the first condition is true for each of the countries in our sample, while analysis of the auxiliary data in the next section will also verify the second condition.

${ }^{4}$ These bounds hold provided $\operatorname{Pr}\left(D_{X}=1\right)<.5$, which is true for all countries in our analysis.
} 


\section{Data}

In order to estimate the bounds on the population obesity rate we need to be able to put limits on the rate of misclassification with self-reported BMI data. To establish these limits we use two data sets; the National Health and Nutrition Examination Survey (NHANES) in the U.S. and the Surveys of Lifestyle Attitudes and Nutrition (SLAN) for Ireland. The NHANES III is a nationally representative survey of 33,994 individuals in the U.S. aged two months of age and older. The interviews were carried out over the period from 1988-1994. The NHANES data have been used previously to examine the extent and nature of misclassification error in self-reported BMI (e.g. Villanueva, 2001, Kuczmarksi et al. 2001) and also in studies that have sought to correct for misclassification error when examining the impact of obesity of labour market outcomes (e.g. Cawley 2004, Burkhauser and Cawley, 2008, Lindeboom et al 2010). The SLAN data are interview based cross-sectional surveys of a nationally representative sample of Irish men and women in 1998, 2002 and 2007. The SLAN data have been used to examine trends in obesity in Ireland (Shiely et. al 2010) and also provide key inputs into health policy making in Ireland (National Task Force on Obesity 2005).

A key feature of both the NHANES data and the SLAN data is that, in addition to self-reported measures of height and weight, both data sets also contain independent measures of the respondent's height and weight. We refer to the latter as recorded measures and treat them as the true height and weight of the respondents. In the NHANES data these recorded measurements were performed in specially-designed and equipped mobile centres, by a team physicians, medical and health technicians, as well as dietary and health interviewers. In the SLAN data the physical examinations were carried out by nurses given specific training and based on documented procedures. Comparing obesity status on the basis of self-reported and recorded measures of BMI, allows us to derive bounds for the misclassification rates and also to examine the validity of the monotonicity assumptions presented in Section 2. Since the misclassification bounds are a key component in the construction of the obesity bounds the availability of two independent auxiliary data sources, is attractive in that it allows us check the robustness of our estimated misclassification rates. Both auxiliary data sets have advantages and disadvantages. The NHANES data has much larger samples than the SLAN data (the 2002 SLAN data used in this analysis only 
contains recorded measures for 147 men and 184 women). On the other hand the timing of the SLAN survey is more consistent with the timing of the ECHP data on which on our overall analysis is based and there is no guarantee that misclassification rates based on US data will necessarily apply to European countries. The availability of the SLAN data allows us to consider the extent to which misclassification bounds based on U.S. data may be applicable more generally.

In order to compare obesity rates across Europe we use data from the European Community Household Panel (ECHP). The ECHP is a dataset explicitly designed to facilitate international comparisons and has been used by Brunello and D'Hombres (2007) to examine the impact of body weight on wages. The ECHP provides self-reported BMI for ten European countries for the periods 1998-2001. ${ }^{5}$ We focus on data for the latest year and restrict attention to individuals aged between 18 and 65. Summary statistics for each of the ten countries are given in Table 1. The sample size ranges from 3109 in Denmark to 10866 in Italy. In general obesity rates are higher for men than for women. In keeping with Brunello and D’Hombres (2007) we find that the importance of obesity based on self-reported height and weight varies in a substantial way across countries. ${ }^{6}$ The countries in Table 1 are ordered on the basis of overall obesity rates; Italy has the lowest obesity rate at $7.5 \%$, while Finland has the largest reported obesity rate at $12.7 \%$. These differences across countries are also apparent when we condition on gender. For example the female obesity rate is twice as high in Italy (6.6\%) than in Finland (13\%). In this paper we examine the extent to which these differences across countries remain after accounting for misclassification in self-reported BMI. To do this we combine the estimated misclassification rates based on the auxiliary data with the self-reported measures of BMI in the ECHP to estimate the obesity bounds for each of the ECHP countries.

\footnotetext{
${ }^{5}$ France, Germany, the Netherlands, the U.K. and Luxembourg also participated in the ECHP but the height and weight data needed to construct BMI was not available for these countries.

${ }^{6}$ Our obesity rates differ to those reported in Brunello and D’Hombres (2007) because we look at all respondents, whereas they focus on employees working at least 15 hours. They also trim the sample excluding people with $\mathrm{BMI}<15$ or $\mathrm{BMI}>35$. These cut-off points correspond approximately to the bottom $.05 \%$ and top $2 \%$ of the sample respectively. We include all observations in our analysis.
} 


\section{Results}

Table 2 reports the estimated misclassification probabilities using the NHANES and SLAN data. The first two columns report the results for women, while the third and fourth columns provide the estimates for men. Looking at the first row we see that estimated the misclassification rates in the self-reported data was approximately $6 \%$ for both men and women in the NHANES data and $10-11 \%$ in the SLAN data. However, the Irish and U.S. misclassification rates estimates are not statistically significantly different from each other given the standard error on the SLAN estimate.

We next consider the empirical validity of the monotonicity assumptions discussed in Section 2. Both auxiliary data sets provide clear support for the direct monotonicity assumption (Assumption 2). This can be seen by comparing the probabilities in the second and third rows of Table 2. Very few people report BMI's above the obesity threshold when their true BMI is below 30. In contrast the proportion of the NHANES sample that report BMI's below 30 when their recorded measure exceeds the obesity threshold is $27 \%$ for women and $25 \%$ for men. The corresponding estimates based on the Irish data are 32\% and 40\% respectively. From this it is clear that the likelihood of misclassification is greater among those who actually obese than among the non-obese. The auxiliary data also provide some support for the indirect monotonicity assumption (Assumption 3). The condition is only violated in one of the four samples we consider (women in the SLAN data).

Although the misclassification rates in the Irish data are slightly higher than in the U.S. data, the estimates across the two data sets are consistent with each other. Given the larger sample sizes available in the NHANES data we use the point estimates from these data as the basis of our misclassification bounds. We follow Nicoletti et. al (2011) and set the bounds on the misclassification probabilities equal to the estimated values plus twice their standard errors. Therefore we choose $\lambda_{1}=.077, \lambda_{2}=.288$ and $\lambda_{3}=.085$ for women and $\lambda_{1}=.07, \lambda_{2}=.267$ and $\lambda_{3}=.071$ for men. Later we conduct a sensitivity analysis to see how the results change as we vary the misclassification bounds.

Table 4 reports the upper and lower bounds $\left\{\mathrm{LB}^{*}, \mathrm{UB}^{*}\right\}$ on the female and male obesity rates for all ten of the countries. The first row for each country gives the point estimates for the lower and upper bounds, while the corresponding upper and lower 
limits of bootstrapped confidence intervals are given in the second row. We first compare the male and female obesity rates within countries. Despite the general tendency for male BMI to be higher than females we see that the identification bounds for men and women overlap in every country. As a result it is not possible to make any comparisons across gender once measurement error is accounted for.

By comparing the rows table 4 we can determine the extent to which it is possible to make rankings across countries. Looking at the results for females we see that, once we account for likely misclassification in self-reported BMI, it becomes difficult to make strong statements regarding the ranking of obesity rates across countries. To distinguish between countries we require the upper bound for one country to be less than the lower bound for another country. When looking at females we see that, with our baseline estimates of the misclassification bounds, the data can only distinguish between Italy (a low obesity country) relative to Spain and Finland (high obesity countries). It is not possible to classify any of the other countries. However, more meaningful comparisons are possible when we consider the male obesity rates. For men the set of low obesity countries is expanded considerably to include Denmark, Ireland, Greece and Portugal along with Italy. For men it would appear that minimal assumptions on misclassification errors are sufficient to identify bounds that are narrow enough to be informative about the ranking of countries by obesity levels.

\section{Sensitivity Analysis}

Even though we derived our misclassification bounds from validation data, the choice of bounds is still to some extent arbitrary. One can examine the sensitivity of our findings to changes in the misclassification probabilities by altering $\lambda_{1}, \lambda_{2}$ and $\lambda_{3}$ For instance, in the analysis in section 4, the misclassification bounds used for women were larger than those used for men. To examine whether this accounts for the gender differences noted in section 4 we repeat the analysis for females except this time we use the male bounds on the misclassification rates. Since these are lower we will observe tighter bounds on the true female obesity rate, which in turn may facilitate more meaningful ranking for women. The results in the first two columns of Table 4, show that using the lower male misclassification bounds when constructing bounds on the true female obesity adds Portugal and Austria to the set of countries which have 
substantially higher obesity rates than Italy, though it still is not possible to classify many of the countries.

Given this finding one might be interested in knowing the largest misclassification error that one could tolerate and still make meaningful obesity rankings across countries using our raw data for women. Since we know that male misclassification rates are too high to permit broad rankings we use $\lambda_{1}=.07$ as a starting point and then reduce the misclassification rate in increments of .005. We adjust $\lambda_{2}$ and $\lambda_{3}$ accordingly so as to keep the ratio between these parameters and $\lambda_{1}$ equal to the ratio implied by the estimates used in the previous section. We then recalculate $\left\{\mathrm{LB}^{*}, \mathrm{UB}^{*}\right\}$ for each new limit and examine the results. The key findings are reported in columns 4-7 of Table 4. The results in the fourth and fifth columns show that reducing $\lambda_{1}$ to .06 adds Belgium and Sweden to the set off low obesity countries (along with Italy) relative to Finland and Spain. However, even with this lower limit it s still difficult to rank most of the countries. The results in the sixth and seven columns show that an upper bound of $\lambda_{1}$ equal to .05 (approximately $75 \%$ of the point estimate obtained in the NHANES data) is required in order to substantially expand the set of low income countries. If one could bound the misclassification rate at this lower level then the raw data would identify a set of low obesity countries consisting of Denmark, Belgium, Ireland, Italy Greece and Sweden, a high obesity set consisting of Spain and Finland and an indeterminate group consisting of only Austria and Portugal. Comparing the male bounds in Table 3 with these latest female bounds in Table 4 also shows that this lower limit on misclassification also permits gender rankings within countries. In particular, with an upper bound of $\lambda_{1}$ equal to .05 there is no overlap between the male and female obesity bounds in Belgium, Italy or Spain. If we could accept this limit on measurement error then the raw data would identify the higher male obesity rates in these countries.

\section{Conclusion}

We examine the robustness of obesity rankings across ten European countries taking account of potential measurement error in self-reported BMI. Our results for men are promising. Despite the presence of measurement error our analysis reveals that minimal assumptions on the rates of misclassification error are sufficient to 
construct bounds which are narrow enough to be informative about the ranking of countries by male obesity levels.

However, it is more difficult to obtain meaningful rankings by female obesity levels. With our baseline estimates it is only possible to rank three of the 10 countries on the basis of female obesity rates. Given the levels of measurement error observed in the data no other meaningful comparisons are possible. Further sensitivity analysis suggests that for women meaningful rankings only emerge when the misclassification rate is bounded at approximately $75 \%$ of the rate observed in auxiliary data. A similar limit on misclassification rates is also needed before we can begin to observe meaningful gender differences in obesity rates within countries. Thus despite the costs involved in obtaining clinical measures of height and weight our analysis suggest that such measures may be required in order to make meaningful comparisons of obesity rates both within and between countries. The ease of obtaining self-reported measures of BMI must be weighed against the biases and subsequent loss of information associated with such measures. 


\section{References}

Burkhauser, R., Cawley, J., 2008. Beyond BMI: The Value of More Accurate Measures of Fatness and Obesity in Social Science Research. Journal of Health Economics 27, 519-529.

Brunello, G., d’Hombres, B., 2007. Does Body Weight Affect Wages? Evidence from Europe. Economics and Human Biology 5, 1-19.

Cawley, J., 2004 The Impact of Obesity on Wages. Journal of Human Resources 39, 451-474.

Conor Gorber, S., M. Temblay, D. Moher and B. Gorver (2007), “A Comparison of Direct vs Self-Reported Measures for Assessing Height, Weight and Body Mass Index: A Systematic Review,” Obesity Reviews, 8, pp. 307-326.

Dauphinot, V., H. Wolff, F. Naudin, R. Gueguen, C. Sermet, J-M Gaspoz and M Kossovsky (2009): "New Obesity Body Mass Index Threshold for Self-Reported Data”, Journal of Epidemiology and Community Health, Vol. 63, pp. 128-132.

Elgar, F.J., Stewart, J.M., 2008. Validity of Self-Report Screening for Overweight and Obesity. Evidence from the Canadian Community Health Survey. Canadian Journal of Public Health 99(5), 423-7.

Faeh, D., J. Braun and M. Bopp (2009), "Underestimation of Obesity Prevalence in Switzerland: A Comparison of Two Methods for Correction of Self-Report," Swiss Medical Weekly, 139 (51-52), pp. 752-56.

Kuczmarski, M., R. Kuczmarski, M. Najjar (2001), "Effects of Age on Validity of self-reported height, weight and body mass index: findings from the third National Health and Nutrition Examination Survey, 1988-1994," Journal of the American Dietetic Association, 101, pp. 28-34.

Lindeboom, M., Lundborg, P., van der Klaauw, B., 2010. Assessing the Impact of Obesity on Labor Market Outcomes. Economics and Human Biology 8, 309-319.

Madden, D. (2012), “Self-Reported and Measured Obesity in Ireland: An Analysis using ROC Curves,” mimeo University College Dublin.

Molinari, F (2008), "Partial Identification of Probability Distributions with Misclassified Data,” Journal of Econometrics, 144, pp. 81-117.

National Task Force on Obesity (2005), “Obesity: The Policy Challenges," http://www.dohc.ie/publications/pdf/report_taskforce_on_obesity.pdf

Nicoletti, C., F. Peracchi and F. Foliano (2011), "Estimating Income Poverty in the Presence of Missing Data and Measurement Error,” Journal of Business \& Economic Statistics, 29, 1, pp. 61-72. 
Nyholm M, B. Gullberg. J. Merlo, C. Lundqvist-Persson, L. Rastam, U. Lindblad (2007), "The validity of obesity based on self-reported weight and height: Implications for population studies,” Obesity (Silver Spring), 15(1):197-208.

O’Neill, D and O.Sweetman, (2012) “The Consequences of Measurement Error when Estimating the Impact of BMI on Labour Market Outcomes,” IZA Working paper No. 7008.

Plankey MW, Stevens J, Flegal KM, Rust PF 1997, "Prediction equations do not eliminate systematic error in self-reported body mass index," Obesity Research 5:308-14.

Shiely, F., Perry, I., Lutomski, J., Harrington, J., Kelleher, C., McGee, H., Hayes, K., 2010. " Misclassification Patterns of Measured and Self-Report Based Body Mass Index Categories - Findings from Three Population Surveys in Ireland. BMC Public Health 10, 56.

Spencer, E.A., Appleby, P.N., Davey, G.K., Key, T.J., 2002. Validity of Self-Reported Height and Weight in 4808 EPIC-Oxford Participants. Public Health Nutrition 5(4), 561-565.

Villanueva, E., 2001. The Validity of Self-reported Weight in US adults: a Population Based Cross-Sectional Study. BMC Public Health 1(11).

WHO, 2009. Global Health Risks: Mortality and Burden of Disease Attributable to Selected Major Risks. World Health Organisation, WHO Press. 
Table 1.

Summary statistics for ECHP data

\begin{tabular}{|c|c|c|c|c|}
\hline Country & $\begin{array}{c}\text { Total Sample } \\
\text { Size }\end{array}$ & $\begin{array}{c}\text { Overall } \\
\text { Obesity Rate }\end{array}$ & $\begin{array}{c}\text { Male } \\
\text { Obesity Rate }\end{array}$ & $\begin{array}{c}\text { Female } \\
\text { Obesity Rate }\end{array}$ \\
\hline Italy & 10866 & .075 & .085 & .066 \\
\hline Ireland & 3142 & .085 & .085 & .085 \\
\hline Sweden & 4406 & .091 & .099 & .082 \\
\hline Denmark & 3109 & .091 & .091 & .091 \\
\hline Greece & 6817 & .093 & .099 & .088 \\
\hline Portugal & 8270 & .095 & .088 & .103 \\
\hline Belgium & 3338 & .100 & .117 & .085 \\
\hline Austria & 4331 & .104 & .109 & .099 \\
\hline Spain & 8897 & .123 & .136 & .110 \\
\hline Finland & 4433 & .127 & .123 & .130 \\
\hline Average & & .098 & .103 & .093 \\
\hline
\end{tabular}

Table 2

Misclassification Rates from NHANES III and SLAN data ${ }^{7}$

\begin{tabular}{|c|c|c|c|c|}
\hline & \multicolumn{2}{|c|}{ Women } & \multicolumn{2}{|c|}{ Men } \\
\hline & NHANES & Slan 2002 & NHANES & Slan 2002 \\
\hline & $\begin{array}{c}\text { Estimated } \\
\text { Value } \\
\text { (SE) }\end{array}$ & $\begin{array}{c}\text { Estimated } \\
\text { Value } \\
\text { (SE) }\end{array}$ & $\begin{array}{c}\text { Estimated } \\
\text { Value } \\
(\mathrm{SE})\end{array}$ & $\begin{array}{c}\text { Estimated } \\
\text { Value } \\
(\mathrm{SE})\end{array}$ \\
\hline $\operatorname{Pr}\left(D_{X^{*}} \neq D_{X}\right)$ & $\begin{array}{c}.067 \\
(.005) \\
\end{array}$ & $\begin{array}{c}.103 \\
(.022) \\
\end{array}$ & $\begin{array}{c}.06 \\
(.005) \\
\end{array}$ & $\begin{array}{c}.116 \\
(.026) \\
\end{array}$ \\
\hline $\operatorname{Pr}\left(D_{X}=1 \mid D_{X^{*}}=0\right)$ & $\begin{array}{c}.007 \\
(.002)\end{array}$ & $\begin{array}{c}.0357 \\
(.0157)\end{array}$ & $\begin{array}{c}.012 \\
(.002)\end{array}$ & 0 \\
\hline $\operatorname{Pr}\left(D_{X}=0 \mid D_{X^{*}}=1\right)$ & $\begin{array}{c}.268 \\
(.009)\end{array}$ & $\begin{array}{l}.318 \\
(.07)\end{array}$ & $\begin{array}{c}.248 \\
(.0095)\end{array}$ & $\begin{array}{c}.40 \\
(.075)\end{array}$ \\
\hline $\operatorname{Pr}\left(D_{X^{*}}=0 \mid D_{X}=1\right)$ & $\begin{array}{l}.0285 \\
(.003)\end{array}$ & $\begin{array}{c}.143 \\
(.058)\end{array}$ & $\begin{array}{l}.0595 \\
(.005)\end{array}$ & 0 \\
\hline $\operatorname{Pr}\left(D_{X^{*}}=1 \mid D_{X}=0\right)$ & $\begin{array}{c}.075 \\
(.005)\end{array}$ & $\begin{array}{c}.094 \\
(.0238)\end{array}$ & $\begin{array}{c}.061 \\
(.005)\end{array}$ & $\begin{array}{l}.139 \\
(.03) \\
\end{array}$ \\
\hline
\end{tabular}

\footnotetext{
${ }^{7}$ The misclassification rates for the SLAN data are based on the numbers reported in table 2 of Shiely et. al (2010).
} 


\section{Table 3}

Estimated Bounds by Country for Females and Males. For each country the estimates of the lower and upper bounds are reported in the first row, while corresponding lower and upper limits of the bootstrap 95\% confidence interval are reported in the second row.

\begin{tabular}{|c|c|c|c|c|}
\hline \multirow[b]{2}{*}{ Country } & \multicolumn{2}{|c|}{$\begin{array}{c}\text { Women } \\
\left(\lambda_{1}=.077, \lambda_{2}=.288 \text { and }\right. \\
\left.\lambda_{3}=.085\right)\end{array}$} & \multicolumn{2}{|c|}{$\begin{array}{c}\text { Men } \\
\left(\lambda_{1}=.07, \lambda_{2}=.267\right. \\
\text { and } \lambda_{3}=.071\end{array}$} \\
\hline & $\mathrm{LB}^{*}$ & $\mathrm{UB}^{*}$ & & \\
\hline \multirow[t]{2}{*}{ Denmark } & .0912572 & .1281702 & 0914397 & 1247472 \\
\hline & .0766416 & 1486977 & .0769698 & 1444879 \\
\hline \multirow[t]{2}{*}{ Belgium } & .0848036 & .1191062 & .1170145 & .1596379 \\
\hline & .0719549 & .1371522 & .1010124 & .1814689 \\
\hline \multirow[t]{2}{*}{ Ireland } & .0850932 & .1195129 & .0848564 & .1157659 \\
\hline & .0716808 & .1383505 & .0707111 & .1350636 \\
\hline \multirow[t]{2}{*}{ Italy } & .0655977 & .0921316 & .0846039 & .1154215 \\
\hline & .0588768 & .1015709 & .077203 & .1255183 \\
\hline \multirow[t]{2}{*}{ Greece } & .0881684 & .123832 & .098455 & .1343179 \\
\hline & .0788576 & .1369089 & .0880616 & .1484972 \\
\hline \multirow[t]{2}{*}{ Spain } & 1097507 & .1541442 & .1355278 & 1848947 \\
\hline & .1002781 & .1674484 & .1257112 & 198287 \\
\hline \multirow[t]{2}{*}{ Portugal } & .1026124 & .1441185 & .0877891 & .1197669 \\
\hline & .0932521 & .157265 & .0791215 & .1315917 \\
\hline \multirow[t]{2}{*}{ Austria } & .0993619 & .1395532 & .1090313 & .1487467 \\
\hline & .0870581 & .1568338 & .0960975 & .1663918 \\
\hline \multirow[t]{2}{*}{ Finland } & .1303961 & .1831406 & .1230558 & .1678797 \\
\hline & 1167559 & 2022981 & .109786 & 1859831 \\
\hline \multirow[t]{2}{*}{ Sweden } & .0823212 & .1156196 & .0998626 & .1362382 \\
\hline & .0708273 & .1317628 & .0871652 & .1535607 \\
\hline
\end{tabular}




\section{Table 4}

Estimated Bounds by Country for Females with alternative misclassification bounds. For each country the estimates of the lower and upper bounds are reported in the first row, while corresponding lower and upper limits of the bootstrap 95\% confidence interval are reported in the second row.

\begin{tabular}{|c|cc|cc|cc|}
\hline & \multicolumn{2}{|c|}{$\begin{array}{c}\text { Women } \\
\left(\lambda_{1}=.07, \lambda_{2}=.267\right. \\
\text { and } \lambda_{3}=.071\end{array}$} & $\begin{array}{c}\text { Women } \\
\left(\lambda_{1}=.06, \lambda_{2}=.2247 \text { and }\right. \\
\lambda_{3}=.066\end{array}$ & $\begin{array}{c}\text { Women } \\
\left(\lambda_{1}=.05, \lambda_{2}=.1872 \text { and }\right. \\
\lambda_{3}=.055\end{array}$ \\
Country & LB $^{*}$ & $\mathrm{UB}^{*}$ & & & \\
\hline Denmark & .0823212 & .1123072 & .0823211 & .117705633 & .0823211 & .1061797 \\
\hline Belgium & .0848036 & .1156939 & .0848036 & .109381711 & .0848036 &. $\mathbf{1 0 4 3 3 5 1}$ \\
\hline Ireland & .0850932 & .1160889 & .0850931 & .109755153 & .0850931 & .1046914 \\
\hline Italy & .0655977 & .089492 & .0655976 & .084609400 & .0655976 & .0807057 \\
\hline Greece & .0881684 & .1202843 & .0881683 & .113721624 & .0881683 & .1084748 \\
\hline Spain & .1097507 & .1497281 & .1097507 & .141558965 & .1097507 & .1350278 \\
\hline Portugal & .1026124 & .1399896 & .1026124 & .132351833 & .1026124 & .1262455 \\
\hline Austria & .0993619 & .1355551 & .0993619 & .128159288 & .0993619 & .1222464 \\
\hline Finland & .1303961 & .1778937 & .1303961 & .168187905 & .1303961 & .1604282 \\
\hline Sweden & .0823212 & .1123072 & .0823212 & .106179787 & .0823212 & .1012809 \\
\hline
\end{tabular}

